\title{
Feature
}

\section{Endowment Strategies for the University of Delaware Botanic Garden through Case Study Analysis}

\author{
Matthew Stephens ${ }^{1}$, Aaron Steil ${ }^{1}$, Melody Gray $^{1}$, Abby Hird ${ }^{1}$, \\ Sonya Lepper ${ }^{1}$, Edward Moydell ${ }^{1}$, Julie Paul ${ }^{1}$, \\ Catherine Prestowitz ${ }^{1}$, Casey Sharber ${ }^{1}$, Treenen Sturman ${ }^{1}$, \\ and Robert E. Lyons ${ }^{2}$
}

ADDITIONAL INDEX WORDs. public garden, fundraising, public horticulture, university gardens, development, public garden management

Summary. The University of Delaware Botanic Garden (UDBG), located in Newark, is in transition, moving from its initial founding as a public garden by dedicated faculty and a volunteer group to an organized and efficient entity with widely recognized achievements and reputation. To make this leap, UDBG is faced with the particular need for an endowment to fund its operations, staff, and collections to continue future success. An endowment will provide a steady source of monetary support to operate and maintain UDBG. This study was conducted to discover the best endowment strategies based on the experience of four other public gardens associated with universities. These interviews were compiled and compared. The resulting recommendations for UDBG are based on the following five areas: organizational structure, planning, current strategies, the endowment, and the donor. The insights into how all five of these areas affect endowments may also be beneficial to other university public horticulture entities seeking to build an endowment.

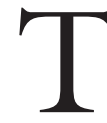
The University of Delaware Botanic Garden, originating from early course-related plantings in 1950, received its title in 1991 . It encompasses 12 gardens over 15 acres (6.1 ha), located around the University of Delaware's College of Agriculture and Natural Resources in

$\overline{{ }^{1} \text { Graduate Student, Longwood Graduate Program in }}$ Public Horticulture, University of Delaware, Department of Plant and Soil Sciences, 125 Townsend Hall, Newark, DE 19716.

${ }^{2}$ Director, Longwood Graduate Program in Public Horticulture, University of Delaware, Department of Plant and Soil Sciences, 126 Townsend Hall, Newark, DE 19716.
Newark (Fig. 1). While continuing to provide an outdoor classroom for various coursework, UDBG now also serves as a public garden for the community, green industry professionals, students, faculty, and staff. Its mission is "to educate students and the public about plants and demonstrate environmentally sound ways of using them aesthetically in the landscape." (Fig. 2). In conjunction with its original mission of teaching in horticulture, UDBG provides 1 -year-long internship and one to three internships each summer. As it continues to further its mission and provide training for interns, UDBG will need to include more modern technology and displays, incorporate more educational interpretation and opportunities, and provide for continual upkeep and administrative management.

The infrastructure of UDBG currently includes an autonomous Friends Group and an Operations Committee. Currently, J. Frett, professor of horticulture at the University of Delaware, serves as the coordinator of UDBG, a role that involves many of the duties a future director would perform. UDBG desires to hire additional staff members, and understands the need for an endowment to fund both this director and future staff. Unlike some forms of financial support, an endowment would provide a stable monetary base to continually fund UDBG's operations and maintenance (Fisman and Hubbard, 2005). The construction, development, and maintenance of an endowment are vital to UDBG's growth and relevance as a viable educational and aesthetic garden.

UDBG financial resources are limited and dependent upon an undiversified source base (Fig. 3A). Like other similarly funded institutions, UDBG is concerned about unexpected expenses and wishes to maintain a cash reserve to handle them since few other additional funding options exist in the current university structure. To transition successfully, UDBG is faced with the particular need for an endowment to fund its operations, staff, and collections to continue future success. This research was conducted to provide comparative information between UDBG and four other university-based gardens. The results are a compilation of successful endowment strategies that can serve as recommendations for UDBG to start the process on its own.

\section{Materials and methods}

To aid in UDBG's endowment development, this study focused on four university-based gardens and arboreta in varying stages of development and with different endowment structures. The locations included Cornell Plantations, associated with Cornell University; the JC Raulston Arboretum (JCRA) at North Carolina State University; the Minnesota Landscape Arboretum (MLA), associated with the University of Minnesota; and the State Botanical Garden of Georgia (SBGG) at the University of Georgia 


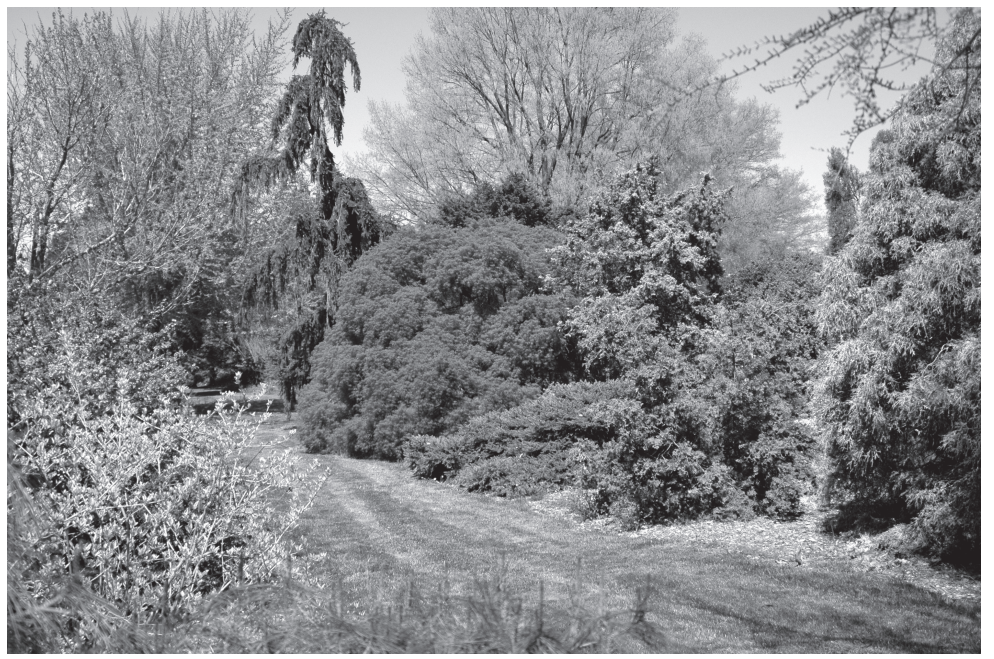

Fig. 1. University of Delaware Botanic Garden is 12 gardens over 15 acres (6.1 ha), located around the University of Delaware's College of Agriculture and Natural Resources.

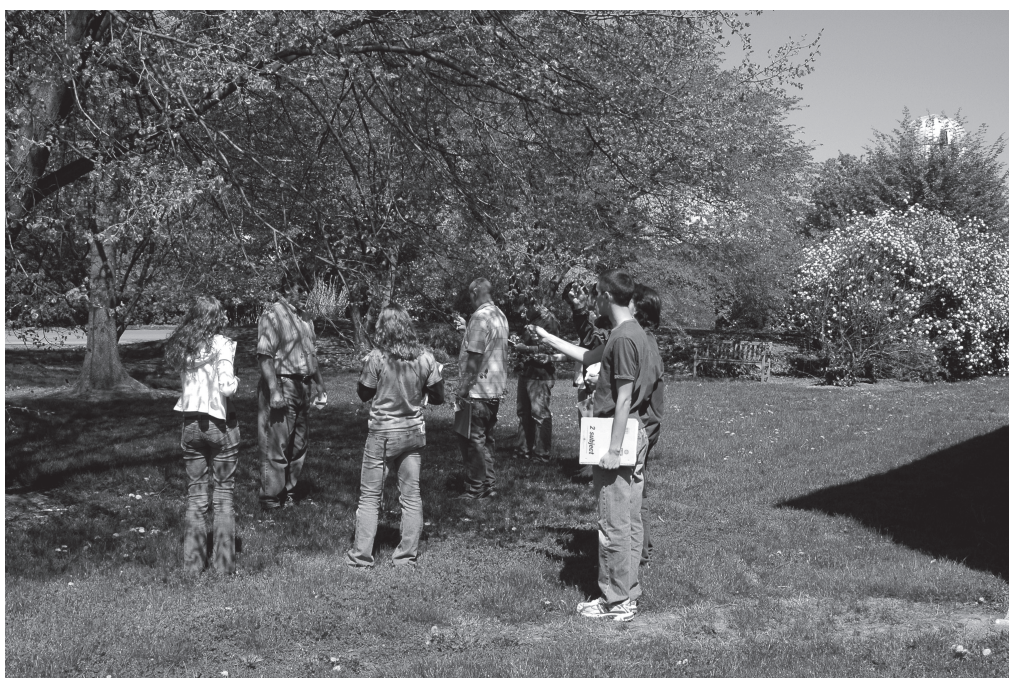

Fig. 2. University of Delaware students use the University of Delaware Botanic Garden (UDBG) for courses in plant identification and botanical gardens management, one major component of UDBG's stated mission.

(Table 1). These sites were chosen based on diversity in size of staff and financial resources, known functions as teaching gardens, known possession of endowments, and diversity in management of those endowments. In addition to these specific sites of study, an advisory task force of eight individuals was assembled to aid in discussion and interpretation of results based on their personal, relevant experiences and professional expertise (Table 2).

With the aid of the task force, questions were developed for interviews conducted with directors and/or some of their selected staff, such as directors of development or college deans, at each study site. Questions were the same for each institution, but were adapted for UDBG interviews (Table 3 ) because they were in the process of endowment development, whereas the other interviewees already had established endowments. Interviewees received the questions in electronic form prior to the interviews, with the exception of UDBG interviews. The questions were constructed to gather information about the institution (annual visitation, staff size, and mission statement), as well as determine their philosophies and strategies for building and maintaining the endowment at their organization. The questions related to institutional information, annual visitation, staff size, and mission statement were closeended in nature (Table 4). The ques- tions specifically about endowments were open-ended and subdivided into five primary categories that preliminary research showed as necessary for the construction of an endowment: organizational structure, planning, current strategies, the endowment, and the donor (Table 5).

Interviews were conducted by groups of at least two individuals, whenever possible, and were digitally voice recorded. Interviews were conducted by different individuals due to the time constraints of the project, but each interviewer was trained in interviewing techniques so as not to introduce interviewer bias or inconsistencies between interview sites into the study. Each interview followed a phenomenological interview format that uses the same questions and probes for all participants, but the order can be changed for each interview to allow the discussion to proceed more naturally. Pertinent sections for interviews were transcribed and then reviewed, coded, and summarized by at least three individuals. These transcriptions, as well as summaries, were then sent back to the interviewee for review and further comment. This participant feedback was important to the external validity and applicability of the statements made during the interview (Johnson and Christensen, 2004).

As each individual listened to the recordings and read the transcripts, he/ she created a summary by organizing statements and answers to questions into the previously mentioned five categories (Shoemaker et al., 2000). This summary was completed by at least three separate individuals, with at least one non-interviewer for each site. This data triangulation was important for several reasons. Multiple people listening and summarizing major themes independently of each other helped ensure accurate interpretation. Also, including at least one non-interviewer per site summary helped prevent potential bias that interviewers may have had (Johnson and Christensen, 2004).

Finally, a writing and editing committee compiled all interview summaries and recorded ensuing recommendations from both interviewers and task force members. At this time, the task force also made recommendations for the interpretation of the results, helping to ensure that they corroborate with interview data. These recommendation-summaries of the interviews 
A. University of Delaware Botanic Garden

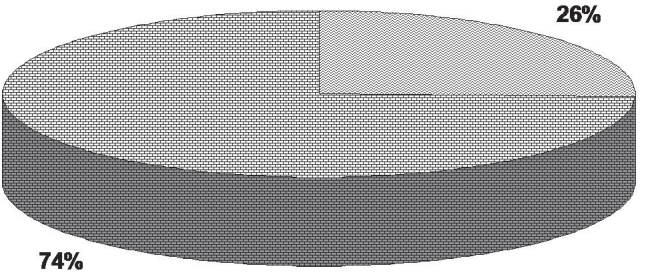

C. Cornell Plantations

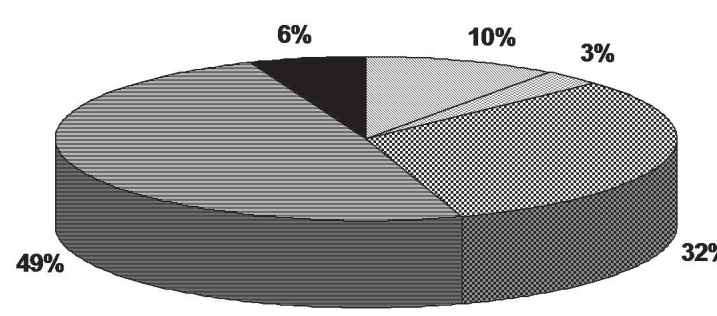

E. Minnesota Landscape Arboretum

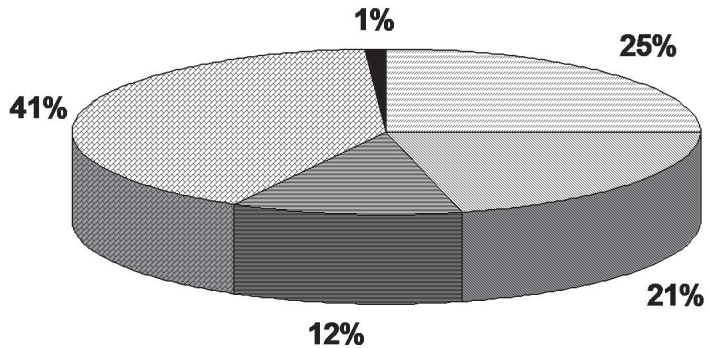

B. State Botanical Garden of Georgia

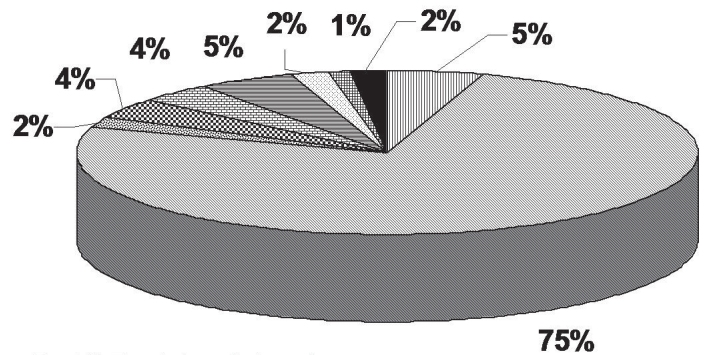

D. JC Raulston Arboretum

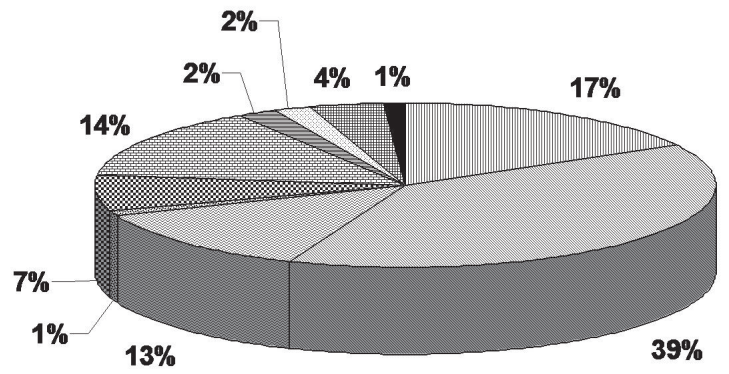

|d Memberships

㢈酌 Fundraising events

Earned income

Endowment

$\square$ University support

Corporate support

College support

Department support

Individual support

Green industry support

Foundation support

Other

Fig. 3. The percentage breakdown for the funding components of five university-based gardens. Listed categories contribute a minimum of $1 \%$ of annual funding and represent the only sources provided by these organizations.

Table 1. People and organizations interviewed to use as models for the development of endowment formation strategies for the University of Delaware Botanic Garden.

\begin{tabular}{lll}
\hline Name & \multicolumn{1}{c}{ Title } & \multicolumn{1}{c}{ Affiliated organization } \\
\hline Mr. Joe Bradley & Director of Development & College of Agriculture and Natural Resources, \\
Dr. John Frett & $\begin{array}{l}\text { Professor of Horticulture, Coordinator } \\
\text { of University of Delaware Botanic Garden }\end{array}$ & $\begin{array}{l}\text { College of Agriculture and Natural Resources, } \\
\text { University of Delaware, Newark }\end{array}$ \\
$\begin{array}{l}\text { Ms. Laura Hunsinger } \\
\text { Dr. Jeff Lewis }\end{array}$ & $\begin{array}{l}\text { Director of External Relations } \\
\text { Director }\end{array}$ & Cornell Plantations, Cornell University, Ithaca, N.Y. \\
Dr. Robin Morgan & Dean & The State Botanical Garden of Georgia, \\
Mr. Peter Olin & Director & University of Georgia, Athens \\
Ms. Anne Porter & Director of Development & University of Delaware, Newark \\
& & $\begin{array}{l}\text { Minnesota Landscape Arboretum, } \\
\text { University of Minnesota, Chaska }\end{array}$ \\
Dr. Donald Rakow & Director & JC Raulston Arboretum, \\
\end{tabular}


Table 2. Members of the task force used to advise and interpret interviews conducted at university-based gardens that were used as models for the development of endowment formation strategies for the University of Delaware Botanic Garden.

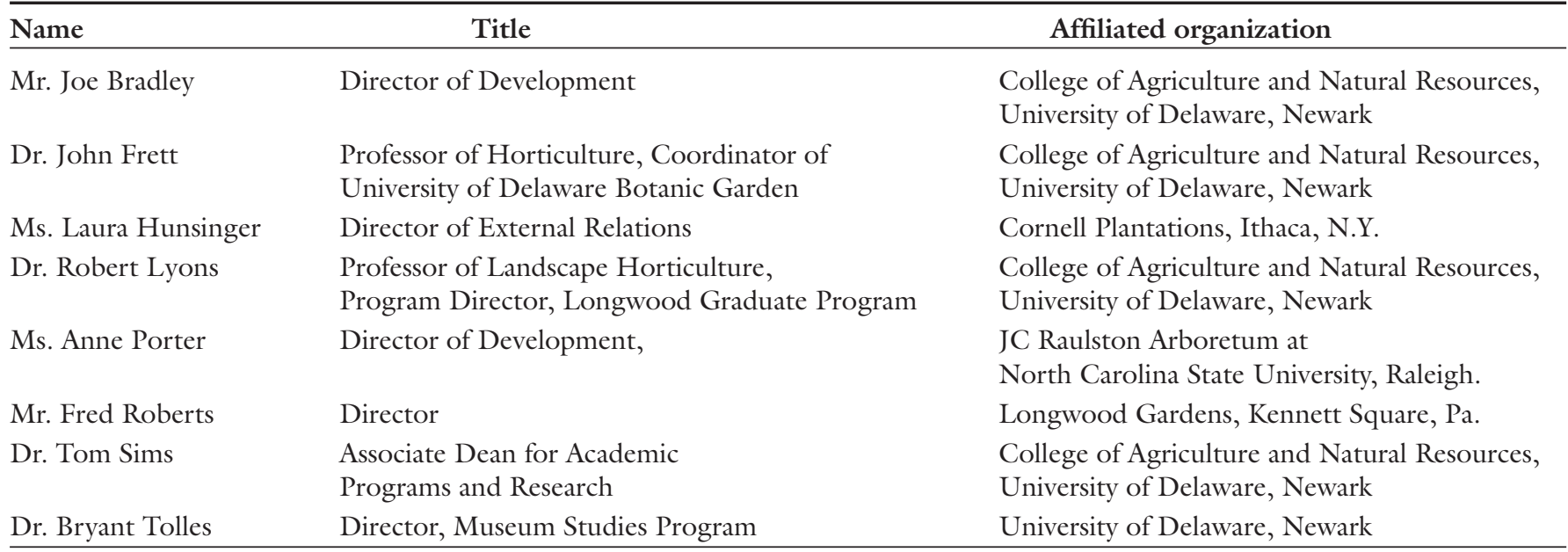

Table 3. Open-ended interview questions about endowment strategies asked at the University of Delaware Botanic Garden.

\section{Organizational structure}

1. Does your mission statement guide your organization through major decisions?

2. What is the organizational structure of the University of Delaware Botanic Garden (UDBG)? To whom does the UDBG report?

3. How does the College of Agricultural Sciences and Natural Resources and the University of Delaware help support the UDBG?

4. How has the University and the College of Agricultural Sciences and Natural Resources leadership supported the UDBG, and what role has it played in fundraising? What are the strengths of this relationship? What are the weaknesses?

5. How can the UDBG achieve a prominent place in the College of Agricultural Sciences and Natural Resource's future and in the eyes of university leadership?

6. What obstacles does the UDBG face in its quest for prominent positioning?

Planning

7. How should fundraising be incorporated into the newly developed UDBG strategic plan?

Current strategies

8. Has the UDBG ever conducted a fundraising campaign? If so, what types? (capital, expendable operations, etc)

9. What ongoing fundraising methods does your organization conduct, (small gifts, large gifts, planned giving, membership, plant sales, etc.) and what is the percentage of total funds raised from each activity?

10. Are you permitted to spend in advance of events leading to anticipated additional revenues? (fundraising events, deficit spending)

11. Who is responsible for fundraising at your organization? How successful has this person been and why? (examples)

12. What role does/should UDBG's executive director play in fundraising? How about the soon to be created Board of Advisors?

The donor

13. Could you generally characterize your major donors? (age, sex, income level, relation to institution, etc.) What audience profiles do you currently cultivate or target for major financial support? How did the organization identify these individuals or entities?

14. What promotional/educational materials are or will be provided to potential donors? How have they been developed? What (new) information do they include? What has been the most successful marketing tool?

15. What program incentives do you offer to your donors?

16. How do you provide recognition and appreciation for your donors?

17. What did I neglect to ask you, or is there anything else you would like to add?

conducted at the four institutions and subsequently coded into respective categories-were reflected in the final written report submitted to UDBG on endowment building strategies.

\section{Results and discussion}

Results are divided into five subcategories, in accordance with the division of the interview questions. Organizational structure focuses on how the internal order of a garden or arboretum can enhance endowment establishment and growth. Planning explores how organizational direction affects endowment. Current strategies seeks techniques, events, and actions that UDBG can use to promote endowment growth. The endowment focuses on endowment-type possibilities and generating funds for endowment establishment. The donor provides insights in cultivating and stewarding those donors who can aid in endowment es- tablishment and growth. These results were presented to UDBG, and UDBG will use them to plan and establish its endowment.

Organizational structure. Several key organizational techniques are vital for supporting and encouraging the administration of an endowment: carefully defined staff roles, authoritative lines, and partnerships; clear and constant communication among staff, partnering organizations, 
Table 4. Close-ended interview questions and documents collected about institutional statistics at each study site except the University of Delaware Botanic Garden.

\section{Closed-ended questions}

1. Does the director of the garden report to the:

Dean of college (yes or no)

Chairperson of the department (yes or no)

Other, please specify (yes or no)

2. What does the university provide?

Positions, please specify (yes or no)

Funding, please specify (yes or no)

Facilities, please specify (yes or no)

Services (maintenance), please specify (yes or no)

Other, please specify (yes or no)

3. What are the percentages of funding for the garden?

Memberships

University support

College support

Department support

Individual support

Fundraising events

Endowment

Corporate support

Green industry support

Other, please specify

4. Who funded the master plan if one exists?

University (yes or no)

College (yes or no)

Department (yes or no)

Private (yes or no)

Other, please specify (yes or no)

5. What ongoing fundraising methods does your organization conduct?

(Please list a percentage for each and a hard copy, if available)

Memberships

Annual gifts

Large gifts

Planned giving

Plant sales

Other, please specify

Information and documents collected

Name of organization

Website address

Number of full-time staff

Source of funding for full-time staff

Number of part-time staff

Source of funding for part-time staff

Number of volunteers

Acreage of institution

Annual visitation

Annual budget

Size of primary endowment

Number of other endowments

Percentage of annual budget from endowment

Yearly percent draw from endowment

Number of staff members dedicated to fundraising

Age of institution

Mission of institution

Proximity to campus

Mission statement

Organizational chart

Strategic plan

Master plan

Annual report

Development and fundraising brochures

Supplemental organizational materials and donors; and a strong understanding and adherence to desired leadership practices at all levels of the garden or arboretum.

STRENGTHEN AND DEFINE RELATIONSHIP WITH PARENT UNIVERSITY And/OR Department. Directors at all four study sites benefit from their relationship with their university, both monetarily and through services; these relationships must be clearly defined for collaboration and smooth operation. Both Cornell Plantations and the SBGG possess strong support from their affiliated universities, in terms of leadership, decision-making, and politics. SBGG receives nearly $75 \%$ of its annual operating income from the University of Georgia (Fig. 3B). Cornell University and the college contribute 13\% of Cornell Plantations' operating budget (Fig. 3C). The success of these gardens, the MLA, and the JCRA is contingent on the strength of their relationships with their respective parent universities and organizations and staff understanding of how their roles influence these relationships. UDBG needs to strengthen its relationship with the University of Delaware as it matures and communicate how staff roles influence that relationship.

MAINTAIN CLEAR AND CONSTANT COMMUNication. Communication is crucial to linking gardens to their overseeing universities, whether through status reports, joint advisory board and college board meetings, or joint faculty and staff meetings between garden faculty and staff and those of the university. Research has shown that it is important that each constituency be kept well informed of each other's actions (Poderis, 2006). However, communication must also occur at a mission level. Cornell Plantations has found benefits through a close integration of its mission with that of the university's for greater momentum and support in daily operations and campaigns. To maintain its relationship with the University of Delaware, UDBG should increase interaction and keep in continual contact with university personnel. It should also align its mission with the University of Delaware's for greater support.

STRONG UNDERSTANDING AND ADHERENCE TO LEADERSHIP PRACTICES. Understanding desired leadership traits and choosing leaders with those traits to propel the garden or arboreta into the future are influential factors 
Table 5. Open-ended interview questions about endowment strategies asked at each study site except the University of Delaware Botanic Garden.

Organizational structure

1. How does the larger institution (university or college) help support the organization (budget line, resources, positions, etc.)?

2. Does the garden receive "line item" funding from the larger institution?

3. How has the leadership of this larger institution supported your organization, and what role has it played in your fundraising? Please provide specific examples. What are the strengths of the relationship? What are the weaknesses?

Planning

4. How is fundraising integrated into your strategic planning efforts?

5. Did you have a master plan during the most intense parts of fundraising? How did the master plan, or lack of, affect your efforts at fundraising?

6. Were/Are funds raised to specifically implement all or parts of the master plan?

\section{Current strategies}

7. Has the organization ever conducted a fundraising campaign? What was this campaign used to fund? (endowment; capital, such as buildings and equipment; operations; , other)

8. Is the garden included in the annual fundraising efforts organized by the larger institution?

9. Are there specific fundraising activities that support the endowment?

10. Who is responsible for fundraising at your organization? How successful have they been and why? Please provide examples.

11. What role does the executive director of the garden play in fundraising? The staff of the garden? The board of advisors/directors of the garden?

12. Is a portion of accepted gifts set aside for project maintenance in perpetuity? If so, what is the ratio?

The endowment

13. What is the relationship between endowment funding, general garden fundraising, and overall institution fundraising campaigns at your institution?

14. How old is your organization's primary endowment? Why was it created? How was it created? What resources were used?

15. What does your endowment fund?

16. What challenges have you encountered with creating, maintaining, and expanding your endowment? What strategies have been employed to meet or exceed these challenges?

17. What types of things have been the most successful for receiving endowment funding? What have been the least successful?

18. What is the minimum amount that could start an endowment at your institution?

The donor

19. Please generally characterize your major donors (age, sex, annual income, relation to institution, etc)? What audience profiles do you currently cultivate or target for major financial support? How did the organization identify these individuals/entities?

20. What promotional/graphics/data are provided to potential donors? How were they developed? What information is provided? Which of these tools is the most effective?

21. What program incentives do you provide to your donors?

22. How do you steward your donors?

23. What were the strengths of your endowment creation?

24. What mistakes did you make along the way of developing the primary endowment?

25. What advice would you offer to institutions trying to create an endowment?

26. What did we forget to ask you, or is there anything else you would like to add?

in potential monetary development, particularly in establishing a board. The board should focus primarily on fundraising and conserving acquired lands. SBGG's board does not focus strongly on fundraising, as it relies very heavily on university support. SBGG currently seeks to branch out into the relatively untapped corporate realm for funds. Keeping the board as one unified entity is desirable; this prevents miscommunication and ensures that all board members will have the means of being involved in all fundraising processes. Cornell Plantations has two boards and has discovered that the logistics of having separate advisory and fundraising boards can be challenging. Choosing board members who will cultivate a large donor base encourages the board to facilitate further financial support for the garden. Boards are integral in the fundraising efforts at the JCRA and at MLA. UDBG should include fundraising as a primary mission for its board as it strives to increase its funding opportunities, a practice already proven to be valuable by other non-profits (Farr, 2004). Additionally, adding board members from the corporate sector will draw in corporate support, just as including community members on the board will strengthen ties to the community. Along with all other board member selections, the college dean should be included to act as a liaison between the garden and the college and university. This will strengthen the board as well as codify the relationship between the garden and university. UDBG is advised to act wisely and accordingly in determining board mission and membership as they mature.

Planning. The establishment of plans for holistic garden or arboreta direction through a master plan is important for future success. In addition, UDBG should set guidelines for implementation of ideas through a strategic plan, and create policy for use and administration of financial gifts for endowment management and growth.

DEVELOP A MASTER PLAN. A master 
plan is instrumental in both shaping and obtaining financial support for the garden. All four sites acknowledge that donors are more likely to give if they can envision tangible results for their financial gifts. Cornell Plantations, MLA, and SBGG all possess working master plans, as well as strategic plans that incorporate fundraising procedures and guidelines. JCRA has found that its lack of a master plan has hindered fundraising to some extent; however, it does possess a strategic plan that incorporates fundraising objectives. A master plan should target specific donor groups, raise foundation support, and generate revenue. For two of the three sites that currently possess master plans, funding to develop a master plan was received from sources outside of the organization, primarily through private donations. MLA, however, used specified monies set aside from the operations budget to finance its master plan. Fundraising was not specifically incorporated into its original master plan; however, it was later added to MLA's "phase one" implementation of the master plan. UDBG must fund the development of a working master plan to ensure the procurement of endowment funds in the future.

DEVELOP A POLICY FOR MANAGING PROJECT COSTS AND MONETARY GIFTS. Guidelines for implementation of financial gifts and for processing project costs need to be included in the master plan as well, and should not be developed stringently, as has been shown to limit an organizations growth (Helms et al., 2005). UDBG should carefully price tangible items at levels sufficient to cover maintenance and replacement costs and include this strategy in both its master and strategic plans. MLA has a 1:1 dollar ratio project installation to project endowment funding written into its master plan, which has enabled MLA to maintain its projects without expending excess operating funds. Planning is a long-term endeavor requiring continual update. A master plan must be a visionary vehicle that considers long-term planning and adaptation. Cornell Plantations, MLA, and SBGG all employ master plans that articulate the growth and direction of the gardens and arboreta, as well as ways they will adapt to the needs of their audiences. UDBG should design a master plan based on its specific vision to guide development; the plan should also set naming and giving policies, and aid in fundraising efforts. These strategies are commonly implemented to assist fundraising (Neigher, 2003).

Current strategies. Current strategies for fundraising to establish or develop an endowment are widely varied. However, three major categories of strategies emerged from the site interviews: director and staff relationships with donors; university campaigns, naming opportunities, and events; and planned and estate giving.

DEVELOP DIRECTOR AND STAFF RELATIONSHIPS WITH DONORS. At this juncture of structural and visionary change, UDBG can re-establish and cultivate new relationships with existing and potential constituencies. The director must be involved in cultivating and stewarding donors and relationships with the corporate sector and the community. The director at Cornell Plantations plays a critical role in stewarding fundraising efforts by setting direction and strategy. A component of UDBG's strategy revolves around the decision of whether to contain the grounds within its current area, as the MLA and JCRA do, or to expand the planting areas to incorporate more of campus grounds, as is done at Cornell Plantations. The decision will affect UDBG's fundraising approaches and will need to be fully supported and implemented by the future director. Currently, MLA's executive director is ultimately responsible for fundraising, as there is a vacancy in the director of development position. SBGG and the JCRA also rely on their directors to catalyze fundraising efforts; however, the JCRA places greater emphasis on the role staff plays in fundraising events, from event coordination to the vital first impressions potential donors receive. UDBG will need to strengthen its staff and director relationships with future and current donors.

Partner With UNIVERSiTy ENDEAVORS AND UTILIZE FUNDRAISING STRATEGIES. In addition to strengthening director and staff involvement in fundraising events, such as its annual plant sale, UDBG can participate in university campaigns as a direct, fundable component within the university list, as well as embark on a membership drive to expand its base of supporters and potential donors. JCRA recently became involved in a capital campaign related to North Carolina State University, and this partnership has proved successful. Collaboration between Cornell
Plantations and the development and alumni relations personnel facilitates fundraising for Cornell Plantations through Cornell University. Cornell Plantations has also held multiple membership drives in connection with various events, and the JCRA relies on membership contributions for $17 \%$ of its annual operating income (Fig. 3D). UDBG should consider tying membership drives to local, annual events, especially those associated with the College of Agriculture and Natural Resources, such as its successful Ag Days. Furthermore, all four of the case study gardens and arboreta took advantage of naming opportunities as a means of procuring funds and stewarding donors. Some of the key naming opportunities that these four sites use and would be applicable to UDBG include: benches, garden sections, parking spaces, events, internships, and named lectures. Other current fundraising strategies JCRA and SBGG employ are special events, such as the "Gala in the Garden" event, and "Gardens of the World Ball," respectively. UDBG could also host events similar to these and allot a portion of the revenues directly towards building an endowment, as JCRA does with its event.

Estate AND PLANNED GIVING. Pursuing estate and planned giving, and possibly pursuing state support, would aid in securing monies to increase the endowment. Cornell Plantations and JCRA both pursue planned and estate giving, as does MLA. SBGG pursues state support, but it is also considering other means of support to offset any possible decline in this source. Developing promotional materials to solicit estate and planned giving is highly recommended for UDBG.

The endowment. Endowment type can be divided into two major categories: multiple small endowments or one primary endowment. The advantage of the first is the ability to attach a visible garden project to the endowment; the disadvantage is the restrictions that then apply to spending endowment funds. The advantage of the latter is the simplicity of directing funds from it, but fundraising can be difficult for this less tangible endowment. UDBG will need to find a balance between the endowment types for simplicity in using funds while being able to fundraise specifically for the endowment. Interviewed sites suggested several strategies for raising funds for the endowment. 
Multiple endowment STRUCTURE. As an example of a multiple endowment structure, Cornell Plantations currently has 97 separate endowment funds; these funds support everything from employee positions to specific garden areas. While historically Cornell Plantations has received unrestricted endowment funding through planned giving, the organization has had the greatest success in procuring funds for specific garden areas. While this type of endowment structure works well for Cornell Plantations, it is not recommended for UDBG, as managing multiple funds would be logistically difficult.

Primary ENDOWMENT STRUCTUREs. The JCRA, like Cornell Plantations, also has multiple endowments; however, it has one primary operational endowment, the "Fund for Excellence," which was established six years ago. As a relatively young arboretum, the JCRA is striving to build one primary endowment, as the director wishes to rely heavily on this as a future source for funding annual operations. MLA has three endowments, but the dividends from each endowment are combined into one single fund, comprising $14 \%$ of the operating budget, that supports all of its activities (Fig. $3 \mathrm{E})$. This structure allows the director to appropriate funds as needed for all projects and areas of the garden, rather than having each project or area funded by a restricted endowment. Although it may be more difficult to build one primary endowment, the benefits are worth the effort. Secondary endowment sources should not be ignored; however, the primary endowment should be carefully balanced with all separate project endowments. This structure is recommended for UDBG as it promotes funding for the gardens as a whole while incorporating funding arising from donors' particular project interests.

BuILDING THE ENDOWMENT. Some gardens and arboreta have found ways to build their less tangible, primary endowments by setting aside specific amounts of funds from specific fundraising events. The JCRA sets aside a minimum of $\$ 10,000$ from its annual "Gala in the Garden" fundraising event. SBGG initiated its endowment by allocating a set amount of funds from its "Gardens of the World" ball and through donations from its board. As a university-based garden, the UDBG may need to raise a substantial amount of funds to begin an endowment. North Carolina State University requires a minimum of $\$ 15,000$ to name any endowment within the University, including any for the JCRA. For SBGG, the minimum contribution to originate a friend endowment is $\$ 10,000$, while the minimum sum required for the University of Georgia is $\$ 25,000$. Based on these initial sums required to begin an endowment, the UDBG needs to embark on an endowment campaign and correlate that campaign in conjunction with the university's activities and campaigns.

The Donor. Communication with the potential donor is crucial to the success of raising funds for an endowment. UDBG can work to raise funds by cultivating and stewarding the right donors, encouraging their involvement with UDBG, and thoroughly communicating their intentions from the beginning.

Cultivate AND STEWARD DONORS. Selecting, stewarding, and cultivating donors are essential for providing new and continued support for gardens and arboreta. In selecting a donor base, it is important to include community members and other individuals who have a vested interest in the gardens and arboreta. Campaigning for an endowment is difficult because it is intangible to the donor and requires trust for future good use and development (Fisman and Hubbard, 2005). Cornell Plantations' primary donors tend to be local members of the community and/ or alumni of Cornell University. People already involved with the JCRA are its best source of donors, particularly the green industry, which provides good contacts for them. MLA has a unique group of donors, most of whom are college-educated women in their sixties, who occupy privileged levels of personal earnings. A diverse range of potential donors should be considered in building a donor base, including the corporate sector, the green industry, the community, alumni, volunteers, and other individuals and organizations (Ehrenberg and Smith, 2003). As the opportunities arise, competitive grants from the corporate sector and government can be considered for short-term program support. All of these potential donor sources should be pursued by UDBG.

ENCOURAGE DONOR INVOLVEMENT. While it would be beneficial to have a broad base of donors, it is also justifiable to seek out a smaller number of donors who are able to contribute a greater amount of financial support. Endowment prospects can be difficult to identify (Hartsook, 1997). Potential and existing board members should be regarded as potential donors. The MLA encourages donors to take ownership in the organization through board membership; this has enabled MLA's creation of a flexible endowment, and hence, has contributed to their success. However, UDBG's board will be new and needs to consider the balance between potential donors, networking opportunities, and the need for visionary leaders and administrators as it selects its members.

Communicate vision TO DONors. Donor stewardship is critical, and active cultivation is necessary to keep donors connected to the gardens. Donors like to be kept informed about how their gift has been used and the issues and/or challenges facing those organizations (Sargeant and Hilton, 2005). All four interviewed sites realize this. The director of Cornell Plantations and director of external relations play a critical role in presenting a successful and professional organizational appearance to potential and existing donors. Communicating the significance and use of endowments, major gifts, annual gifts, and membership dollars ensures that support continues to flow into the organization. The JCRA looks to membership, volunteers, and staff within the college and university advancement teams to provide names of potential donors. Cultivating and stewarding potential donors requires a personal touch; people need to feel that their gifts are appreciated. Such personal involvement has been demonstrated to foster productive relationships between the institution and donor (Poderis, 2006). MLA and SBGG prioritize potential donor cultivation and keeping established donors engaged. The director of UDBG should articulate the organization's vision and serve as the main contact for prominent donors, as is the case for all four of the studied sites.

\section{Conclusion}

The primary purpose of this research was to develop endowment creation strategies for UDBG following a thorough review of other university-based gardens' approaches. 
Clear organizational structure is necessary to develop an endowment; the garden or arboreta must strengthen ties to its affiliated college and university to ensure full support at all levels and stages of development. Creating a board with a clearly defined purpose that incorporates fundraising is vital. Planning must include a strategic and master plan; without them, successful fund-soliciting from donors will be difficult to achieve. UDBG must implement and develop current strategies for fundraising to include innovative and appropriate events, naming opportunities with maintenance costs included, and other means of reaching potential donors. A single endowment needs to be created with care. One primary endowment for operating income has emerged from this research as the best possible scenario for UDBG. Embarking on an endowment campaign in conjunction with the university can add substantial funds to an endowment base. Additionally, building a broader donor base requires careful donor cul- tivation and stewardship. Once these foundational principles are integrated and employed, UDBG will be ready to initiate and build its endowment, and reach its full potential.

\section{Literature cited}

Ehrenberg, R.G. and C.L. Smith. 2003. The sources and uses of annual giving at selective private research universities and liberal arts colleges. Econ. Educ. Rev. 22:223-235.

Farr, L.M. 2004. New directions for philanthropic fundraising. Wiley, New York.

Fisman, R. and R.G. Hubbard. 2005. Precautionary savings and the governance of nonprofit organizations. J. Public Econ. 89:2231-2243.

Hartsook, R.F. 1997. Endowment fundraising made easy. Fund Raising Mgt. 28(4):30-31.

Helms, L., A.B. Henkin, and K. Murray. 2005. Playing by the rules: Restricted endowment assets in colleges and universities. Nonprofit Mgt. Leadership 15(3):341-356.
Johnson, B. and L. Christensen. 2004. Educational research: Quantitative, qualitative, and mixed approaches. Pearson Education, Boston.

Neigher, W.D. 2003. The process is the plan: Defining strategic community futures. Evaluation Program Planning 26:441-457.

Poderis, T. 2006. Designing a communications plan to enhance your fundraising campaign. 25 Jan. 2006. <http://www. raise-funds.com/0401 forum.html>.

Sargeant, A. and T. Hilton. 2005. The final gift: targeting the potential charity legator. Intl. J. Nonprofit Volunteer Sector Mktg. 10:3-16.

Shoemaker, C.A., P.D. Relf, and V.I. Lohr. 2000. Social science methodologies for studying individuals' responses in human issues in horticulture research. HortTechnology 10:87-93. 